\title{
Global prevalence and economic and humanistic burden of astigmatism in cataract patients: a systematic literature review
}

This article was published in the following Dove Press journal:

Clinical Ophthalmology

\section{David F Anderson' Mukesh Dhariwal ${ }^{2}$ Christine Bouchet ${ }^{3}$ Michael S Keith ${ }^{3}$}

'University Hospital Southampton, NHS Foundation Trust, Southampton, UK; ${ }^{2}$ Novartis Ireland Ltd., Dublin, Ireland; ${ }^{3}$ Alcon Laboratories Inc., Fort Worth, TX, USA
Correspondence: Christine Bouchet Health Economics and Outcomes Research, Alcon Laboratories, 620I South Freeway - TA6-15, Fort Worth, TX 76134-2099, USA

$\mathrm{Tel}+18175518154$

Fax +18176156016

Email christine.bouchet@alcon.com
Purpose: To systematically review the published evidence on the prevalence and economic and humanistic burden of astigmatism in cataract patients.

Materials and methods: For this systematic literature review, the Medline, PubMed, Embase, and Cochrane databases were searched from 1996 to September 2015 for available scientific literature that met the inclusion criteria. Studies published in the English language reporting prevalence and humanistic and economic burden in patients diagnosed with cataract and astigmatism were included.

Results: Of 3,649 papers reviewed, 31 studies from 32 publications met the inclusion criteria of this review. Preexisting astigmatism $\geq 1 \mathrm{D}$ was present in up to $47 \%$ of cataract eyes. The cost burden of residual uncorrected astigmatism after cataract surgery was driven by the cost of spectacles, which was estimated to range from $\$ 2,151$ to $\$ 3,440$ in the US and $\$ 1,786$ to $\$ 4,629$ in Europe over a lifetime. In cataract patients, both preexisting and postoperative residual astigmatism were associated with poor vision-related patient satisfaction and quality of life, as well as higher spectacle burden. Astigmatism correction during cataract surgery appears to improve visual outcomes and results in overall lifetime cost savings compared to astigmatism correction with postoperative vision correction.

Conclusion: There is a high prevalence of preexisting astigmatism in cataract patients. Although published data are limited, both preoperative astigmatism and postoperative residual astigmatism affect visual function and vision-related quality of life, resulting in increased humanistic burden. Suboptimal correction of astigmatism during cataract surgery drives the continuous need for vision correction with spectacles in the postoperative period. Patients must bear the out-ofpocket expenses, since payers often do not reimburse the cost of spectacles. Greater access to astigmatism correction during cataract surgery could improve visual outcomes and quality of life in patients. More research is required to gain a better understanding of the disease burden of astigmatism in cataract patients.

Keywords: astigmatism, economic burden, humanistic burden, prevalence, cataract

\section{Introduction}

Cataract is an opacification of the lens that leads to decreased visual acuity (VA) and functional disability. ${ }^{1}$ Cataract is a common and significant cause of visual impairment and the leading cause of preventable blindness worldwide. ${ }^{2}$ Astigmatism, resulting typically from anterior corneal asymmetry, leads to decreased image quality. ${ }^{3}$ Astigmatism is measured in both magnitude and direction. Astigmatism of 1-1.5 D or more negatively impacts reading performance and nighttime-driving ability. ${ }^{4,5}$ Astigmatism in patients with cataract further reduces VA and adversely impacts functional and 
contrast VA. Uncorrected astigmatism can lead to decreased vision and affect patients' vision-related quality of life (QoL) and well-being. ${ }^{6}$

The prevalence of astigmatism and the associated economic and humanistic burden in patients undergoing cataract surgery have been recognized in the international literature, but data from these studies have not been systematically reviewed. Therefore, this systematic literature review was conducted to address this gap and report the published evidence on prevalence, economic burden, and humanistic burden of astigmatism in cataract patients.

\section{Materials and methods}

This review followed a standard, systematic review methodology endorsed by the Cochrane Collaboration ${ }^{7}$ and the National Institute for Health and Care Excellence, the healthtechnology assessment body of the UK. ${ }^{8}$ Findings from this review were reported in accordance with the PRISMA (preferred reporting items for systematic reviews and metaanalyses) guidelines (Figure 1). ${ }^{9}$

A comprehensive literature search was conducted using predefined search strings (Table 1) in electronic databases
(Medline, Medline In-Process, Embase, and the Cochrane Library). The key search terms focused on identifying studies on prevalence, direct and indirect treatment costs, and patient QoL in cataract patients with astigmatism. All studies reporting prevalence, economic burden, and humanistic burden in cataract patients with preexisting astigmatism (PEA) published in English from 1996 to September 2015 were included. Animal and in vitro studies, non-English-language studies, studies published prior to 1996, and studies that did not meet research objectives were excluded. In addition, abstracts and posters from the following conferences (held from 2010 until September 2015) were searched: American Association of Ophthalmology Congress, World Ophthalmology Congress, Royal College of Ophthalmologists UK Congress, and the European Association for Vision and Eye Research Congress. Reference lists of relevant studies, systematic reviews, or literature reviews were also screened to identify any publication not captured through the systematic search.

Following the search process, we screened abstracts of all publications, and excluded publications for further review if they did not fulfill the eligibility criteria. Full-text copies of all

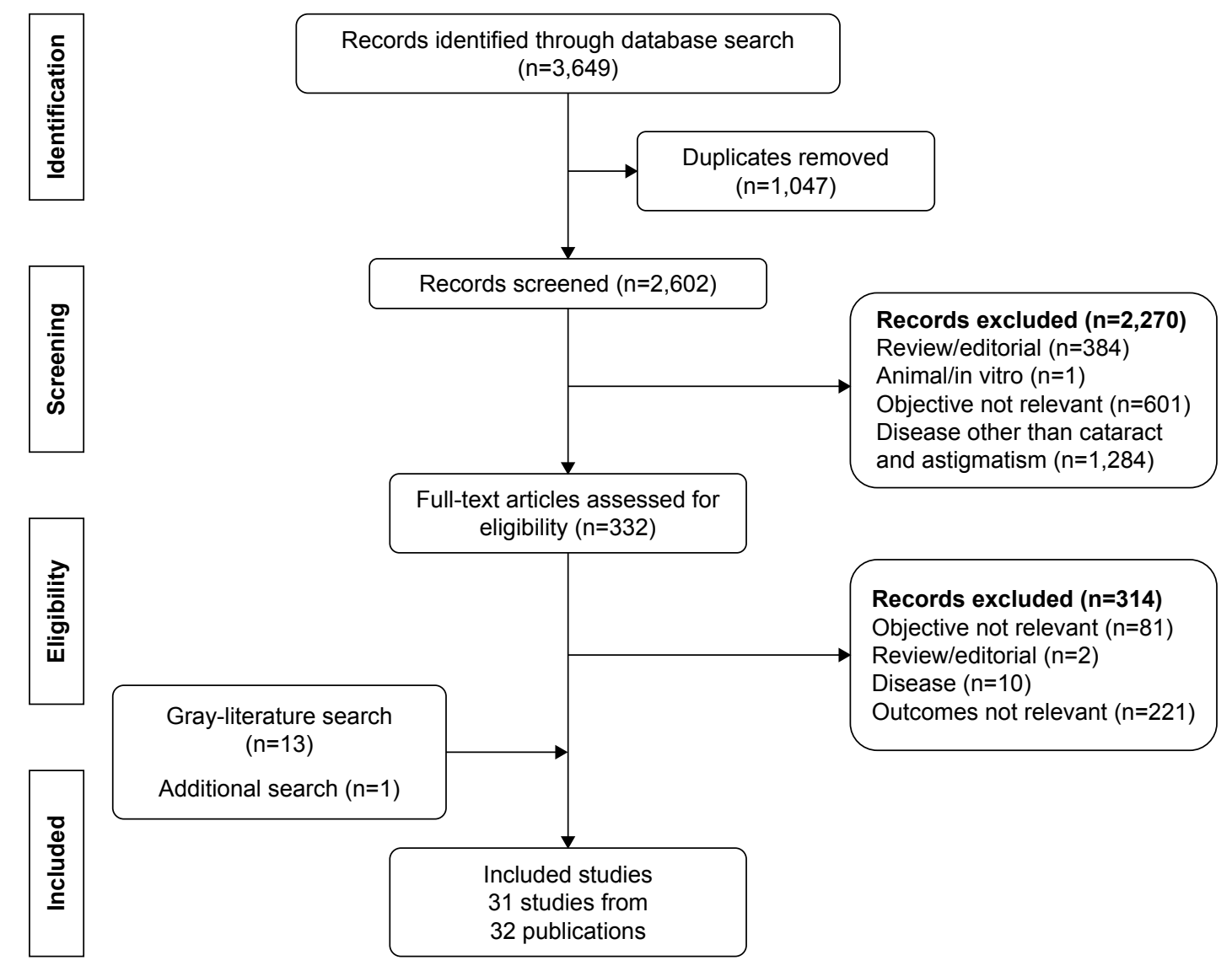

Figure I PRISMA (preferred reporting items for systematic reviews and meta-analyses) flow diagram. 
Table I Search strategy

\begin{tabular}{|c|c|}
\hline & Search terms \\
\hline I & exp cataract/or exp capsule opacification/ \\
\hline 2 & (cataract or (lens adj2 opac*)).ab,ti,kw. \\
\hline 3 & $\begin{array}{l}\text { exp refractive errors/or exp aniseikonia/or exp anisometropia/or exp astigmatism/or exp corneal wavefront aberration/or exp } \\
\text { hyperopia/or exp myopia/or exp presbyopia/ }\end{array}$ \\
\hline 4 & (astig* or ametropia or myopi* or Hyperopi* or nearsightedness or farsightedness or (refractive adj2 (error or aberration))).ab,ti. \\
\hline 5 & I or 2 \\
\hline 6 & 3 or 4 \\
\hline 7 & 5 and 6 \\
\hline 8 & exp “Quality of Life”/ \\
\hline 9 & exp quality-adjusted life years/ \\
\hline 10 & $\begin{array}{l}\text { (QoL or quality adjusted life year or QALY or hrqol or quality of life or DALY or disability adjusted life years or life year* or patient } \\
\text { reported outcome or (years adj3 lost)).ab,ti. }\end{array}$ \\
\hline II & (short-form 36 or SF-36 or SF-6D or euroqol or EQ-5D or HUl or health utility index).ab,ti. \\
\hline 12 & $\begin{array}{l}\text { (National Eye Institute Visual Function Questionnaire or NEI VFQ or cataract TyPE specification questionnaire or visual activities } \\
\text { questionnaire or visual disability assessment or visual function or quality of life questionnaire or VF-I4 or VF-8 or catquest } 9 \text { SF } \\
\text { questionnaire or cataract outcomes questionnaire).ab,ti. }\end{array}$ \\
\hline 13 & $\begin{array}{l}\text { "costs and cost analysis"/or exp “cost allocation"/or exp cost-benefit analysis/or exp "cost control”/or exp "cost of illness"/or } \\
\text { exp "cost sharing"/or exp health care costs/or exp health expenditures/or exp economics, hospital/or exp hospital charges/or exp } \\
\text { hospital costs/or exp economics, medical/or exp fees, medical/or exp economics, nursing/or exp economics, pharmaceutical/or exp } \\
\text { fees, pharmaceutical/or exp prescription fees/ }\end{array}$ \\
\hline 14 & $\begin{array}{l}\text { exp "costs and cost analysis"/or exp "cost allocation"/or exp cost-benefit analysis/or exp "cost control”/or exp "cost savings"/or exp } \\
\text { "cost of illness"/or exp "cost sharing"/or exp health care costs/or exp direct service costs/or exp drug costs/or exp employer health } \\
\text { costs/or exp hospital costs/or exp health expenditures/ }\end{array}$ \\
\hline 15 & exp Health Resources/ \\
\hline 16 & $\begin{array}{l}\text { exp hospitalization/or exp "length of stay”/or exp patient admission/or exp patient discharge/or exp patient readmission/or exp } \\
\text { institutionalization/ }\end{array}$ \\
\hline 17 & $\begin{array}{l}\text { (cost* or economic* or price or hospitali* or length of stay or expenditure or fee* or pharmacoeconomic* or resource* or } \\
\text { productivity* or loss of work or absenteeism or presenteeism or cost effectiveness or cost benefit or incremental cost or ICER).ab,ti. }\end{array}$ \\
\hline 18 & exp epidemiology/or exp molecular epidemiology/or exp pharmacoepidemiology/ \\
\hline 19 & $\begin{array}{l}\text { exp morbidity/or exp incidence/or exp prevalence/or exp mortality/or exp molecular epidemiology/or exp epidemiologic study } \\
\text { characteristics as topic/or exp epidemiologic studies/or exp epidemiologic research design/ }\end{array}$ \\
\hline 20 & $\begin{array}{l}\text { (epidemiolog* or incidence* or prevalen* or mortality or death or survival or risk factor or co-morbid* or morbid* or mortalit* or } \\
\text { death or survival or die* or natural history or disease progress* or prognosis).ab,ti. }\end{array}$ \\
\hline 21 & 18 or 19 or 20 \\
\hline 22 & 13 or 14 or 15 or 16 or 17 \\
\hline 23 & 8 or 9 or 10 or 11 or 12 \\
\hline 24 & 7 and 21 \\
\hline 25 & 7 and 22 \\
\hline 26 & 7 and 23 \\
\hline 27 & 24 or 25 or 26 \\
\hline 28 & exp lenses, intraocular/or exp phakic intraocular lenses/ \\
\hline 29 & (intraocular lens or IOL).ab,ti. \\
\hline 30 & 28 or 29 \\
\hline 31 & toric*.mp. \\
\hline 32 & 30 and 31 \\
\hline 33 & 7 and 32 \\
\hline 34 & 27 or 33 \\
\hline 35 & Limit 34 to English language [limit not valid in CDSR, ACP Journal Club, DARE, CLCMR; records were retained] \\
\hline 36 & Limit 35 to human [limit not valid in CDSR, ACP Journal Club, DARE, CCTR, CLCMR; records were retained] \\
\hline 37 & Limit 36 to humans [limit not valid in CDSR, ACP Journal Club, DARE, CCTR, CLCMR; records were retained] \\
\hline 38 & Remove duplicates from 37 \\
\hline
\end{tabular}

publications that fulfilled the eligibility criteria or those lacking sufficient information in the abstract for exclusion were obtained and reviewed, and the eligibility criteria were reapplied. Finally, data were extracted from eligible publications for full review.
For the economic burden section, costs reported across studies were inflated to 2017 US\$ using consumer price indices published by the Organisation for Economic Co-operation and Development ${ }^{10}$ and currency-exchange rates. ${ }^{11,12}$ 


\section{Results}

The literature search yielded 3,649 citations, of which 31 from 32 publications were identified for inclusion in this review and data extraction performed (Figure 1). In total, 18 studies from 19 publications ${ }^{13-31}$ (one study reported in two publications) reporting prevalence were identified. Five studies $^{32-36}$ reporting economic burden and eight studies ${ }^{37-44}$ reporting humanistic burden were identified.

\section{Prevalence of preexisting astigmatism in cataract}

Table 2 provides a summary of studies reporting the prevalence of PEA in cataract patients. Of 18 studies included in this review, nine were retrospective, five cross-sectional, and four prospective in design. The reported mean age of the astigmatic cataract patients was 60.6-75.5 years. A higher proportion of females compared to males reported having PEA and cataract: $53.7 \%-68.2 \%$ across the studies. PEA was measured in cylinder diopters, with reported means of 0.79-1.09 D.

Across countries, the overall prevalence of astigmatism in cataractous eyes (of any cylinder magnitude) was as follows: Croatia 99\%, ${ }^{17}$ UK 94\%, ${ }^{22}$ South Korea 91.8\%, ${ }^{26}$ and Spain $86.8 \%,{ }^{18}$ indicating that astigmatism is a very common refractive error alongside cataract. However, not all patients would require correction for their astigmatism. In general, cataract and refractive surgeons would aim to correct PEA if it is above a clinically important threshold; however, there is no universally accepted clinically important cylinder diopter-threshold to identify treatment-eligible cataract patients with PEA.

Many studies reported prevalence as a proportion of cataract eyes $\geq 1$ D of PEA. ${ }^{13,16-19,23-28,31}$ Using a $\geq 1$ D threshold, the prevalence of PEA ranged between $23 \%{ }^{26}$ in South Korea and $47 \%{ }^{31}$ in China (Figure 2). At least two studies reported this prevalence as patients who could benefit from PEA correction during cataract surgery.

Lyall et al proposed a widely used disease-severity classification approach in clinical practice, ie, categorizing disease severity into mild, moderate, and severe categories for PEA in cataract patients' severity classification. ${ }^{24}$ The following thresholds to classify PEA in cataract patients into three categories were proposed: $<1.5 \mathrm{D}$ (mild), $\geq 1.5-<2.5 \mathrm{D}$ (moderate), and $\geq 2.5 \mathrm{D}$ (significant). We applied this classification to the data reported in various studies, and generated uniform prevalence figures across geographies. With this approach, the prevalence of mild PEA $(<1.5 \mathrm{D})$ ranged between $74.6 \%{ }^{31}$ (China) and $89.6 \%{ }^{13,26}$ (South Korea), moderate PEA ( $\geq 1.5-<2.5$ D) $8.1 \% 0^{10,13}$ (Sweden) and $18.6 \%{ }^{31}$ (China), and significant PEA ( $\geq 2.5$ D) $2 \%{ }^{26}$ (South Korea) and $6.8 \%{ }^{28}$ (Thailand) (Figure 3). It is evident from the reported data that across countries, the prevalence of clinically relevant PEA in cataract patients is substantial and that these patients could benefit from astigmatism correction during cataract surgery. None of the prevalence studies included in this review reported the prevalence of postoperative astigmatism, which could have provided some insights into astigmatism-correction patterns during cataract surgery.

Astigmatism differs from other common refractive conditions (hyperopia and myopia) in that the refractive error is measured in both magnitude and direction. In addition, it can also be measured based on corneal topographical symmetry: irregular astigmatism, which does not conform to any geometric appearance, and regular astigmatism, which is symmetrical across the meridian. Regular astigmatism is defined as with the rule (WTR) when the axis of the correcting minus cylinder was within $180^{\circ} \pm 30^{\circ}$ (the steep meridian of the cornea being within $90^{\circ} \pm 30^{\circ}$ in this case), against the rule (ATR) when the correcting minus-cylinder axis was within $90^{\circ} \pm 30^{\circ}$, and oblique astigmatism (OA) if it was neither WTR nor ATR. ${ }^{16}$ The prevalence of astigmatic cataract eyes by the type of astigmatism orientation (WTR, ATR, and OA) was reported in five studies and is presented in Figure 4.

The proportion of astigmatic cataract eyes with ATR stigmatism was $39 \%$ in Italy, ${ }^{16} 45 \%$ in Croatia, ${ }^{17} 50 \%$ in New Zealand, ${ }^{29}$ and $52.4 \%$ in Thailand ${ }^{28}$ and China. ${ }^{31}$ The proportion of astigmatic cataract eyes with WTR astigmatism was $15 \%$ in New Zealand, ${ }^{29} 22 \%$ in Croatia, ${ }^{17} 22.7 \%$ in Thailand, ${ }^{28} 30.4 \%$ in China, ${ }^{31}$ and $44 \%$ in Italy. ${ }^{16}$ While the proportion of astigmatic cataract eyes with OA was $15 \%$ in New Zealand, ${ }^{29} 17 \%$ in Italy, ${ }^{16} 17.2 \%$ in China, ${ }^{31} 24.9 \%$ in Thailand, ${ }^{28}$ and $32 \%$ in Croatia. ${ }^{17}$ Based on the reported data, ATR is the most common subtype of regular PEA in cataract patients. These prevalence data on astigmatism subtypes can be helpful for surgeons to plan optimized astigmatism correction during cataract surgery.

Correlations between age and the prevalence and/or severity of PEA in cataract patients were reported in eight studies (four each from Europe and Asia). 14,16,18,19,22,24,28,31 A small increment in the magnitude of astigmatism with age was observed in a Spanish cohort. ${ }^{18}$ Khan and Muhtaseb ${ }^{22}$ reported a gradual increase in the prevalence and severity of PEA with age in the UK population, but Lyall et al, ${ }^{24}$ also a UK-based study, did not report such a trend. Similarly, De Bernardo et al did not identify an increase of astigmatism 


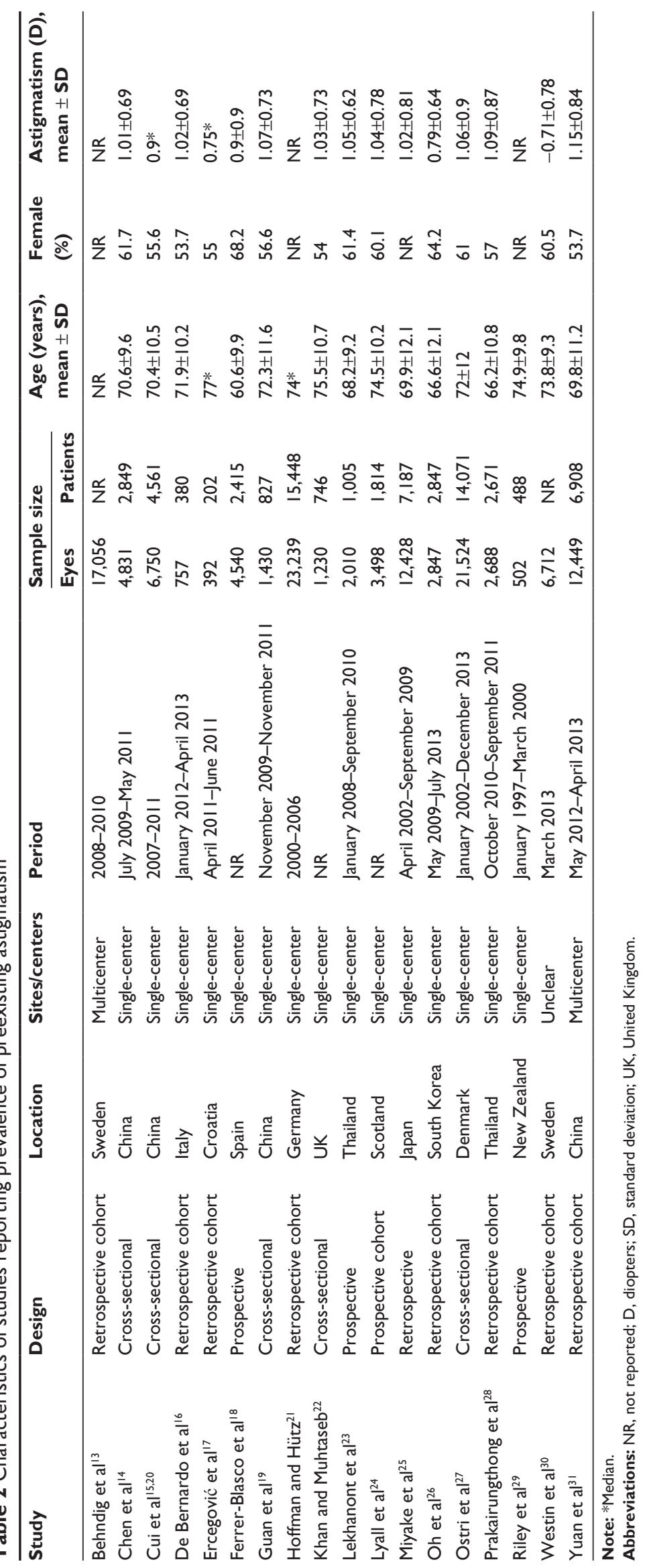




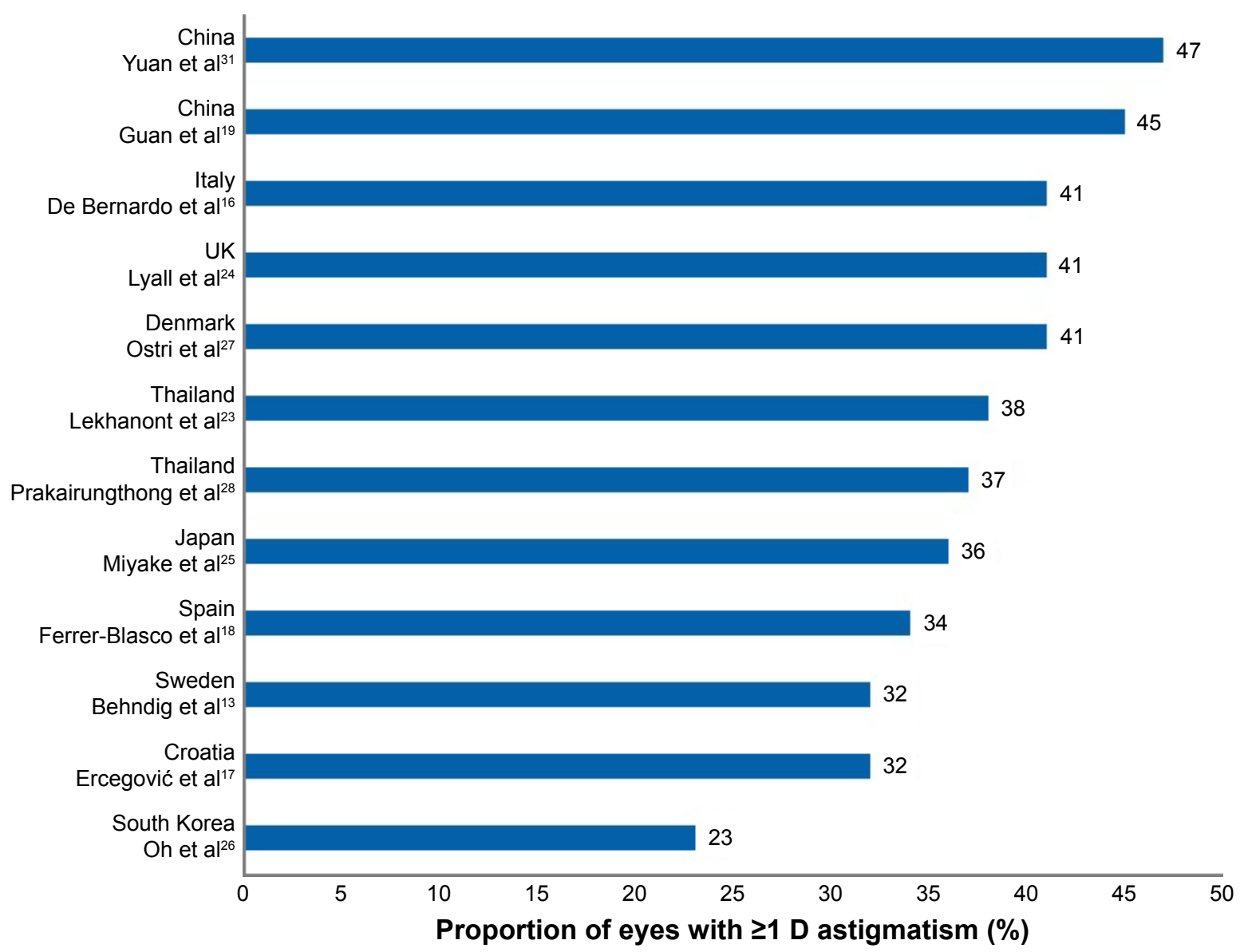

Figure 2 Prevalence of cataract eyes with $\geq$ I D of preexisting astigmatism. Abbreviations: D, diopters; UK, United Kingdom.

with age in an Italian cohort either. ${ }^{16}$ However, this trend appears to be consistently reported across Asia. In a Thai cohort, a significant correlation between astigmatism severity and age was observed $(P<0.001) .{ }^{28}$ Similar positive results were observed in all the three studies from China, which reported a significant increase in PEA severity and age. ${ }^{14,19,31}$ A trend was also observed between advancing age and increasing prevalence of ATR astigmatism in all the studies that reported data on both parameters. ${ }^{16,18,19,21,24}$ Some studies also reported correlations between orientation of regular astigmatism and age. An increase in the frequency of ATR astigmatism was observed with advancing age in cataract patients. ${ }^{16,18,19,21,24}$ Several studies also reported associations of age and the degree of astigmatism, with characteristic changes in the astigmatic axis from WTR to ATR with advancing age ${ }^{45-48}$ Based on the review of evidence, the correlation between advancing age and PEA severity remains inconclusive, as findings differed among studies conducted across similar and different geographies. However, cataract being a primarily an age-related condition, the evidence indicates that surgeons planning cataract surgery in older patients should consider PEA levels and plan for the optimum treatment strategy to improve postoperative visual outcomes.

\section{Economic burden}

The economic burden of cataract has been widely recognized ${ }^{49,50}$ and acknowledged by the ophthalmologic community; ${ }^{51-53}$ however, the economic burden of preexisting and postoperative astigmatism is not widely known. In our search, we identified five studies that reported direct and indirect cost burdens of astigmatism in cataract patients. ${ }^{32-36}$ Table 3 details the characteristics of the included studies. None of the studies reported preoperative economic burden of astigmatism in cataract patients. The studies published were health-economics analyses that reported the estimated cost of astigmatism correction during cataract surgery, evaluated the cost-effectiveness or cost consequence of astigmatism correcting treatment options, and estimated the cost burden of correcting postoperative residual or uncorrected astigmatism with spectacles.

Laurendeau et al conducted a cost-consequence analysis in four European countries (France, Germany, Italy, and Spain) from a societal perspective, comparing monofocal intraocular 


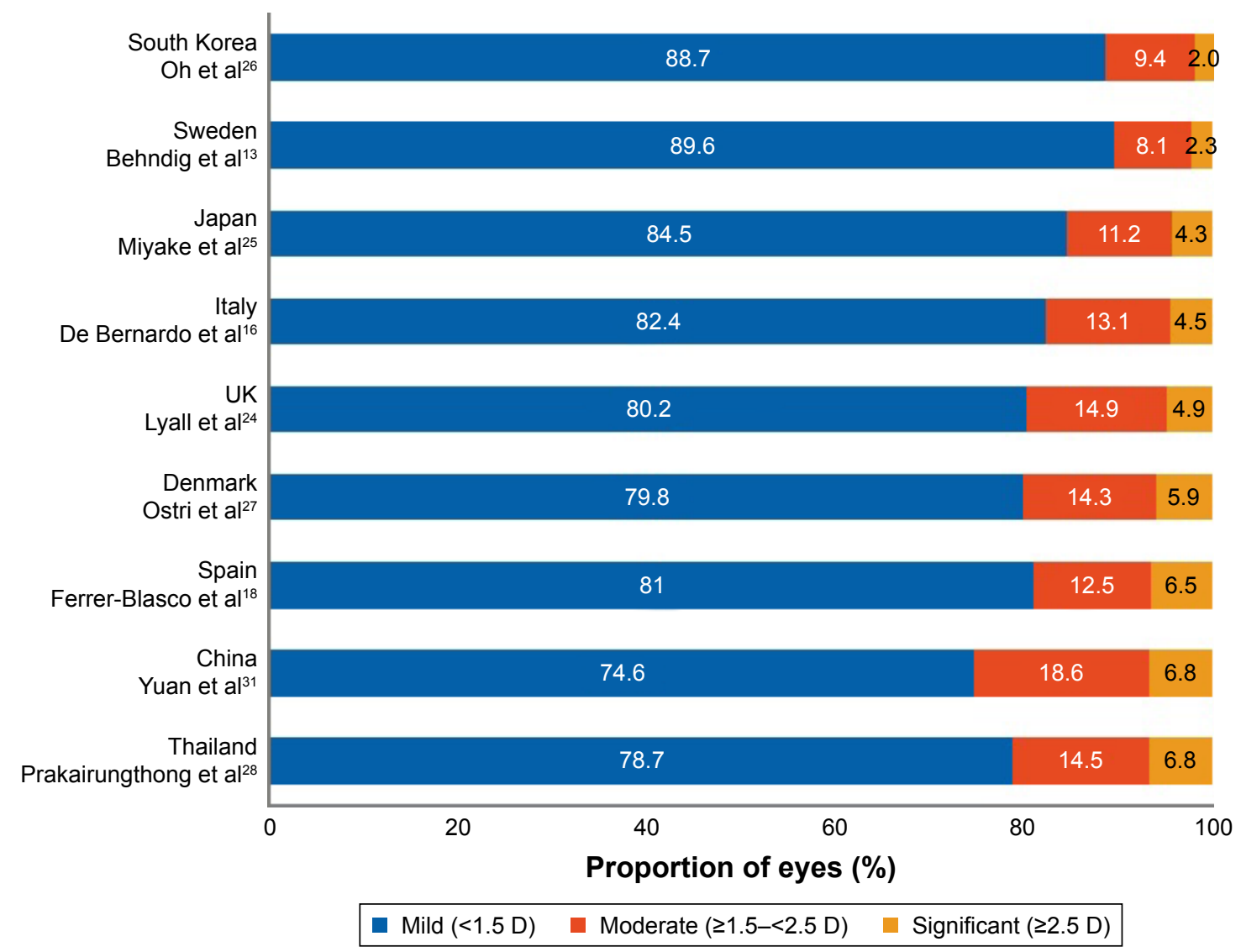

Figure 3 Distribution of preexisting astigmatic cataract eyes with mild, moderate, or significant astigmatism.

Note: Based on the categorization reported by Lyall et al. ${ }^{24}$

Abbreviations: D, diopters; UK, United Kingdom.

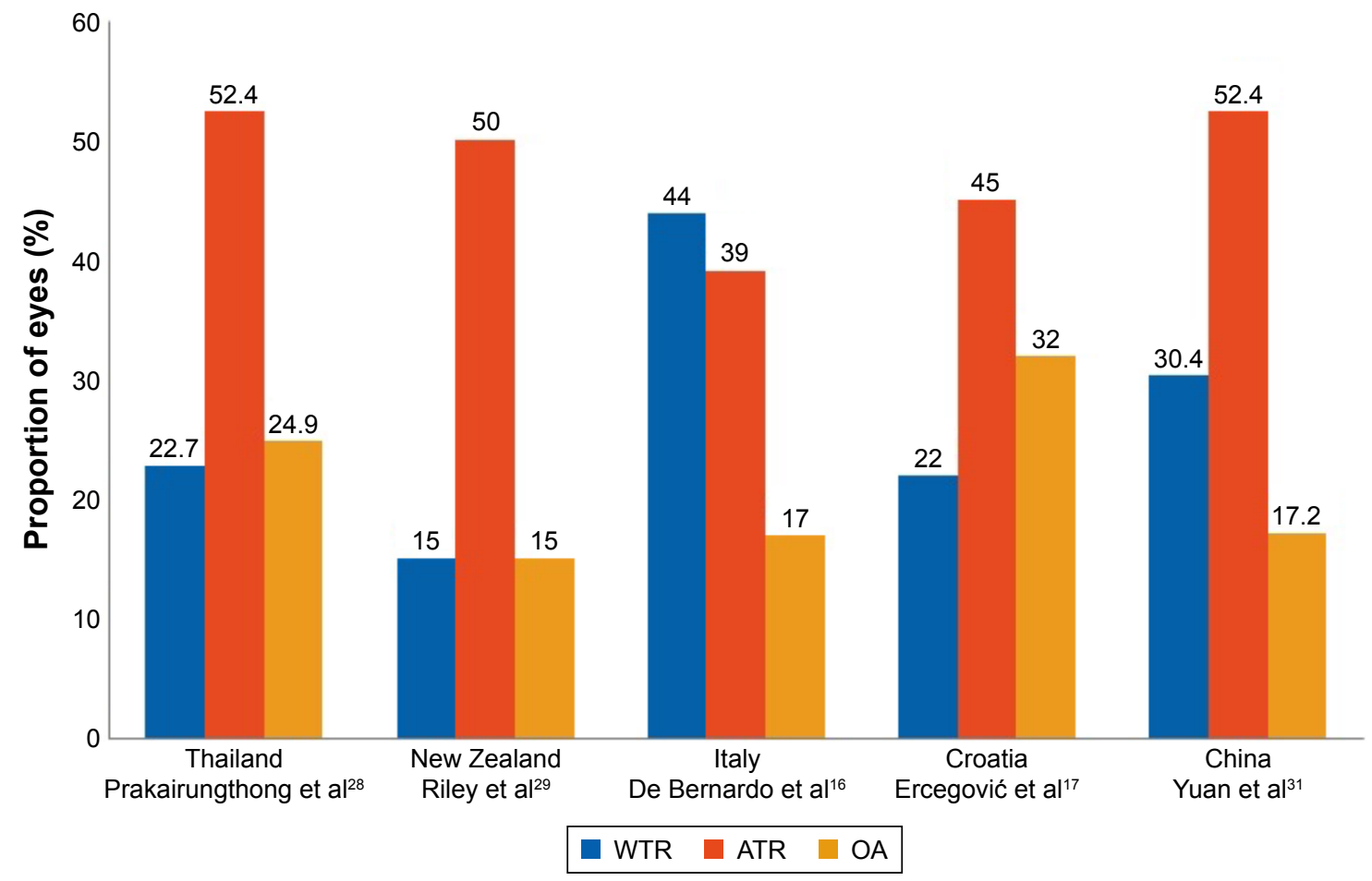

Figure 4 Distribution of preexisting astigmatic cataract eyes by type of orientation.

Abbreviations: ATR, against the rule; OA, oblique astigmatism; WTR, with the rule. 
Table 3 Characteristics of studies reporting economic burden

\begin{tabular}{|c|c|c|c|c|c|c|c|c|}
\hline \multirow[t]{2}{*}{ Study } & \multirow[t]{2}{*}{ Design } & \multirow[t]{2}{*}{ Location } & \multirow{2}{*}{$\begin{array}{l}\text { Cost } \\
\text { year }\end{array}$} & \multicolumn{2}{|c|}{ Sample size } & \multirow{2}{*}{$\begin{array}{l}\text { Age (years), } \\
\text { mean }\end{array}$} & \multirow{2}{*}{$\begin{array}{l}\text { Female, } \\
\%\end{array}$} & \multirow{2}{*}{$\begin{array}{l}\text { Astigmatism (D), } \\
\text { mean }\end{array}$} \\
\hline & & & & Eyes & Patients & & & \\
\hline Laurendeau et $\mathrm{al}^{32}$ & Cost-consequence analysis & Multinational & 2006 & NR & NR & 70 & NR & NR \\
\hline Pineda et $\mathrm{a}^{33}$ & Cost-utility analysis & USA & 2008 & NR & NR & $\geq 65$ & NR & $1.5-3$ \\
\hline Ochoa et $\mathrm{al}^{34}$ & Cost-effectiveness analysis & Colombia & 2013 & NR & NR & NR & NR & $>0.75$ \\
\hline Colin et $\mathrm{al}^{36}$ & Retrospective cohort & France & NR & NR & 580,253 & 73.6 & 66.7 & NR \\
\hline Kim et $\mathrm{al}^{35}$ & Cross-sectional & South Korea & NR & NR & 150 & $>45$ & NR & NR \\
\hline
\end{tabular}

Note: For all studies, costs have been inflated from base year to 2017 and converted to US\$.

Abbreviations: D, diopters; USA, United States of America; NR, not reported.

lenses (IOLs) to toric IOLs with a focus on their ability to reduce spectacle dependence. ${ }^{32}$ The rate of spectacle replacement was estimated to be 2-3 years for many patients (33\%-48\%). A simulated cohort of astigmatic, bilateral IOL recipients undergoing cataract surgery was followed up with a time horizon of 30 years in a Markov model. In this analysis, the estimated cost of cataract surgery per patient, including cost of IOLs (both toric and standard monofocal IOLs considered at parity price), ranged from $\$ 1,510$ in Spain to $\$ 1,740$ in Germany. Patients implanted with toric IOLs in France, Spain, Germany, and Italy were estimated to spend between $\$ 1,786$ and $\$ 3,605$ on spectacles, while in patients implanted with monofocal IOLs, the costs were estimated to be between $\$ 2,313$ and $\$ 4,629$. In all four countries, the lifetime cost-savings associated with toric IOLs ranged from $\$ 443$ to $\$ 978$. Savings in the toric IOL group observed were due to less expensive vision correction with spectacles compared to the standard monofocal IOL group. ${ }^{32}$

Pineda et al conducted a cost-effectiveness analysis comparing toric IOLs with monofocal IOLs (with or without intraoperative refractive correction [IRC] using limbal relaxing incision/peripheral corneal relaxing incision [PCRI]). ${ }^{33}$ They built a decision-analysis model reflecting the treatment pathway for cataract patients with astigmatism from the US health-care perspective over a span of 18 years. Patients with toric IOLs were estimated to achieve an incremental gain of $13 \%$ with regard to spectacle independence versus those with monofocal IOLs without IRC and $4 \%$ compared to those with IRC. The toric IOL group was estimated to achieve an incremental gain of $9 \%$ in uncorrected VA (UCVA) $\geq 20 / 25$ versus the monofocal IOL group without IRC and 5\% compared to the group with IRC. Incremental quality-adjusted life-year (QALY) gains in patients with toric IOLs versus monofocal IOLs without and with IRC were reported to be 0.1 and 0.06 QALYs, respectively. Postsurgery total lifetime costs associated with toric IOLs were comparable with monofocal IOLs, but costs associated with IRC along with monofocal IOLs were higher than those with toric IOLs or monofocal IOLs alone. In addition, the lifetime cost of spectacle use after cataract surgery was estimated to be higher with monofocal IOLs compared to toric IOLs. Patients with toric IOLs saved $\$ 34$ over their lifetime compared with those using monofocal IOLs without IRC. The cost savings were sensitive to UCVA achieved ( $\$ 425$ more if UCVA $\geq 20 / 25$ ), cost of the toric IOLs, and the likelihood of achieving spectacle independence. Compared to the costs in patients with IRC and monofocal IOLs, patients with toric IOLs saved $\$ 230$ over their lifetime. The savings reflected higher spectacle independence in the toric IOL group. The lifetime cost saving per patient could be considered negligible, but it is important to note that the toric IOL group also achieved a higher QALY gain for the duration of this model, indicating that toric IOLs were a dominant treatment strategy for cataract patients with PEA. ${ }^{33}$

Similarly, Ochoa et al conducted a cost-effectiveness study in Colombia to evaluate the cost-effectiveness of toric IOLs versus the use of conventional monofocal IOLs in patients with cataract and PEA $>0.75 \mathrm{D}$ from the perspective of third-party payer. ${ }^{34} \mathrm{~A}$ decision-tree model simulated the cataract-surgery intervention over a time horizon of 5 years. The cumulative cost of treatment of patients with cataract and PEA $>0.75 \mathrm{D}$ with toric IOLs was estimated to be $\$ 1,172$ compared to $\$ 786$ with traditional monofocal IOLs up to 5 years after cataract surgery. The incremental cost-effectiveness ratio with toric IOLs was $\$ 573$ per year of normal vision without additional support compared to traditional monofocal IOLs. A linear relationship between preoperative PEA diopters and ICER was observed, indicating that PEA correction in cataract patients with toric IOL was more cost-effective in patients at the higher end of the severity spectrum. ${ }^{34}$

As a refractive error, astigmatism can affect patients' vision and lead to difficulty in performing job-related activities. However, it is important to note that cataract patients are usually older and mostly outside the workforce population, and thus direct productivity loss could be considered of little 
relevance to society. On the other hand, their caregivers could be part of the working-age population and the condition could be associated with indirect productivity loss. To estimate the direct and indirect costs and associated productivity loss for astigmatic cataract patients, Kim et al conducted a crosssectional survey in South Korea in cataract patients with and without astigmatism $(n=150) .{ }^{35}$ They reported that time spent on health-care appointments related to astigmatism correction with spectacles was 30-60 minutes for $41 \%$ of patients, while $15 \%$ of patients spent over 90 minutes. A relative accompanied two-thirds of patients for optometrist appointments. They also reported that patients with post-cataract surgery astigmatism paid approximately twice as much for their spectacles compared to patients without postoperative astigmatism ( $\$ 452$ and $\$ 223$, respectively). The additional postsurgical lifetime cost of spectacles in cataract patients to correct astigmatism was $\$ 2,164$ per patient, which was greater than the out-of-pocket costs associated with toric IOLs. ${ }^{35}$

Health-care resource utilization is an important contributor to the direct health-care costs and could affect hospital budgets. Resource utilization in astigmatic cataract patients was studied and reported by Colin et al. ${ }^{36}$ Findings suggested that astigmatic cataract patients had longer hospital stay, more comorbidities, and a significant increase in procedures compared to cataract patients without astigmatism. Further, the cost of procedures was higher for astigmatic cataract patients. ${ }^{36}$ However, these data need to be interpreted with caution, since cataract surgery is almost universally an outpatient procedure in the majority of countries. This review did not identify studies that reported health-care resource utilization in astigmatic cataract patients in the postoperative period, which could have provided some insights into the impact of uncorrected astigmatism on health-care resources.

\section{Humanistic burden}

Cataract is known to have impact on patients' QoL. ${ }^{54}$ The QoL of cataract patients is further aggravated by the presence of astigmatism. Astigmatism-related vision distortion can lead to decreased visual performance, which increases spectacle dependence and can affect vision-related QoL. As with economic burden, the impact of astigmatism on patients' vision-related QoL has not been widely acknowledged. We identified eight studies that reported the humanistic burden of astigmatism in patients with cataract. ${ }^{37-44}$

Table 4 provides a summary of the included evidence. Five studies reported data on patient satisfaction with vision, ${ }^{38,40-43}$ and six studies on spectacle dependence in astigmatic cataract patients. ${ }^{37-41,43}$ Only one study reported the

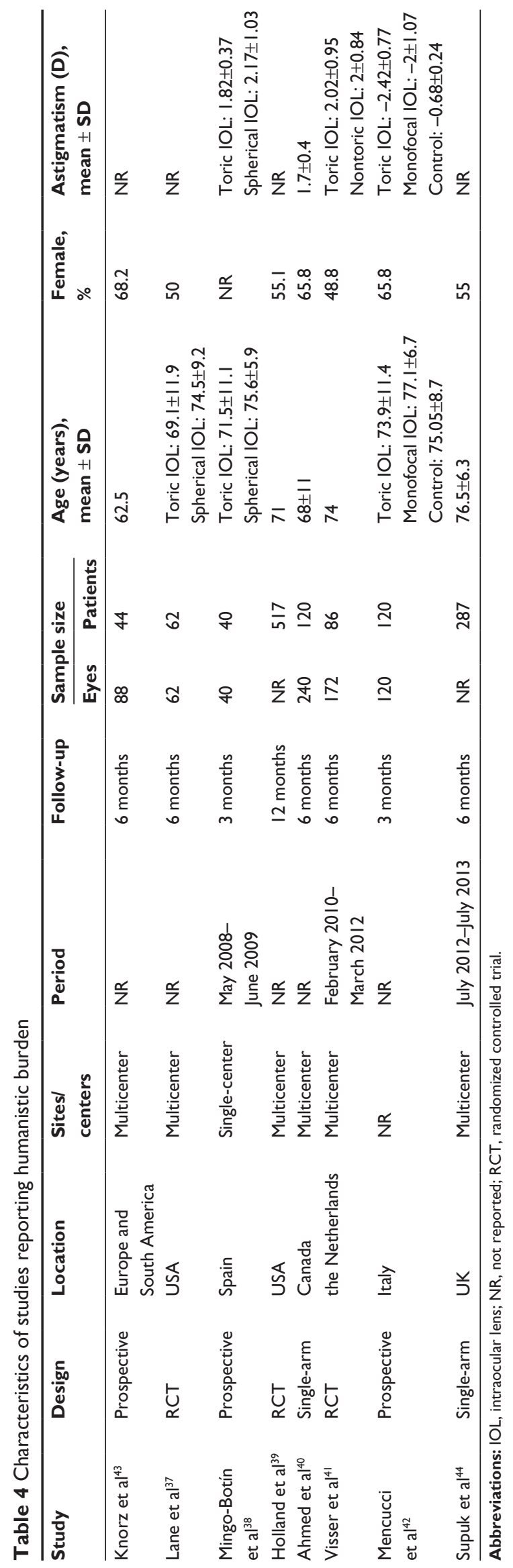


effect of astigmatism on the risk and rate of falls in patients with cataract. ${ }^{44}$ Table 5 summarizes the instruments used to assess vision-related QoL in studies included in this review. Different measures were used to evaluate patient satisfaction with vision: the Patient Satisfaction Scale (0-10), ${ }^{38,40,43}$ standardized 42-item National Eye Institute Refractive Error Quality of Life (NEI RQL-42) questionnaire, ${ }^{41,42}$ Visual Tasks Difficulty Assessment (VISTAS) questionnaire, ${ }^{43}$ and 14-item Visual Function (VF-14) index. ${ }^{38}$ The main findings from each study are reported separately in the following paragraphs, since heterogeneous study designs and different outcomes measures used to report spectacle dependence, satisfaction with vision, and QoL did not allow for evidence summary.

Spectacle independence is becoming an increasingly important outcome in cataract surgery, including in astigmatic cataract patients. ${ }^{41}$ Lane et al conducted a prospective multicenter double-arm study in patients with cataract and corneal astigmatism to assess spectacle independence and patient satisfaction with vision over 6 months of follow-up in patients with bilateral toric ( $\mathrm{n}=40$ patients) and spherical ( $n=22$ patients) IOLs. ${ }^{37}$ At 1 month postsurgery, spectacle independence (defined as no use of spectacles for distance vision) was relatively higher in patients who received toric IOLs (97\% of patients) compared to those who received spherical IOLs ( $50 \%$ of patients). At the end of the 6 -month follow-up, $24 \%$ of patients with toric IOL implantation required prescription glasses of any type (bifocals, distance, or reading) compared to $64 \%$ of patients in the spherical IOL group. ${ }^{37}$
Mingo-Botín et al conducted a randomized controlled trial (RCT) measuring spectacle dependence (defined as need to wear distance-vision spectacles) and patient satisfaction in cataract patients with PEA who were implanted with either toric IOLs ( $n=20)$ or spherical IOLs with PCRI $(n=20) .{ }^{38}$ The VF-14 index was administered to patients prior to surgery and at 3 months after cataract surgery to assess functional impairment related to vision. Presurgery subjective patient satisfaction with vision was poor in both groups and a large increase in VF-14 index scores and reported satisfaction with vision was reported for both groups, with no significant difference between groups. Presurgery, $85 \%$ of patients in the toric IOL group and $80 \%$ of patients in the PCRI group wore spectacles to correct distance vision. At 3 months postoperatively, $15 \%$ of toric IOL patients required distancevision spectacles compared to $45 \%$ of patients treated with spherical IOLs. ${ }^{38}$

Holland et al conducted a large multicenter RCT comparing toric IOLs ( $n=256$ patients) to spherical IOLs ( $n=261$ patients) in cataract patients with PEA, and reported postoperative spectacle dependence (defined as any-use spectacles for distance vision) as one of the treatment outcomes. At 6 months postsurgery, 39\% of patients with toric IOLs reported some degree of spectacle dependence for distance vision compared with $64 \%$ of those with spherical IOLs. ${ }^{39}$

Ahmed et al conducted a single-arm prospective study to evaluate the efficacy of bilateral toric IOL implantation in astigmatic cataract patients $(n=117) .{ }^{40}$ At 6 months postsurgery, $69 \%$ of patients reported independence (defined as no use of spectacles) from distance spectacles. Postsurgery,

Table 5 Instruments used to evaluate quality of life in astigmatic patients with cataract

\begin{tabular}{|c|c|}
\hline Instrument & Summary \\
\hline NEI RQL-42 & $\begin{array}{l}\text { This is a } 42 \text {-item questionnaire that measures patients' satisfaction with distance vision, clarity of vision, and severity and frequency } \\
\text { of glare symptoms, along with the need for spectacles. The scale ranges } 0-100 \text {, with higher scores indicating better QoL and less } \\
\text { dependence on corrective wear (such as spectacles or contact lenses). }\end{array}$ \\
\hline $\begin{array}{l}\text { VISTAS } \\
\text { questionnaire }\end{array}$ & $\begin{array}{l}\text { The questionnaire has three sections. Section I has questions related to subjective experience with tasks at a range of distances with } \\
\text { and without corrective wear. The near-task section comprises ten questions to assess visual acuity less than } 50 \mathrm{~cm} \text { from the patient. } \\
\text { The intermediate-task section comprises I } 2 \text { questions to assess the patient's vision at distances of } 50-90 \mathrm{~cm} \text {. The near-distance-task } \\
\text { section comprises } 13 \text { questions to assess the patient's vision from } 90 \mathrm{~cm} \text { to } 4 \text { m. The distance-task section comprises } 15 \text { questions } \\
\text { to assess vision from more than } 4 \text { m away. Section II of the questionnaire evaluates the patient's use of corrective wear and reliance } \\
\text { on it. Section III of the questionnaire evaluates vision without corrective wear, and includes an assessment of patient satisfaction for } \\
\text { daytime and nighttime vision. } \\
\text { Potential responses for section I of the questionnaire are I= no difficulty, } 2=\text { minor difficulty, } 3=\text { moderate difficulty, } 4=\text { major } \\
\text { difficulty, } 5=\text { cannot accomplish, and } 6=\text { not applicable. A response of "not applicable" could be selected if participants did not } \\
\text { perform a task for reasons other than poor vision or if corrective wear was not worn for the task. Responses for section II, assessing } \\
\text { use of corrective wear, are "none of the time", "some of the time", "half of the time", "most of the time", and "all the time". }\end{array}$ \\
\hline VF-I4 & $\begin{array}{l}\text { The VF-14 is a brief questionnaire designed to measure functional impairment on patients due to cataract. It consists of } 18 \text { questions } \\
\text { covering } 14 \text { aspects of visual function affected by cataracts. }\end{array}$ \\
\hline
\end{tabular}

Abbreviations: NEI RQL-42, National Eye Institute Refractive Error Quality of Life; VF, Visual Function (index); QoL, quality of life; VISTAS, Visual Tasks Difficulty Assessment. 
patients provided satisfaction ratings on a scale of 1 (completely unsatisfied) to 10 (completely satisfied), and $94 \%$ of patients rated their satisfaction as 7 or higher. Patient satisfaction was statistically significantly higher postoperatively at 6 months compared to preoperative values $(P<0.001) .{ }^{40}$

Visser et al conducted an RCT in patients with bilateral cataract and bilateral astigmatism $(\mathrm{n}=86)$ in the Netherlands. ${ }^{41}$ One of the outcome measures was spectacle independence in patients who received bilateral toric $(n=41)$ or aspherical $(n=45)$ IOL implantation. At 6 months postoperatively, spectacle independence (defined as no use of spectacles) for distance vision was achieved in $84 \%$ of patients implanted with toric IOLs compared to $31 \%$ of patients implanted with aspherical IOLs $(P<0.01)$. At 6 months after cataract surgery, no significant differences were identified between the toric IOLs and aspherical IOLs for NEI RQL-42 subscales. Mean scores on the NEI RQL-42 satisfaction with corrections subscale was similar for patients implanted with toric or aspherical IOLs ( 87 and 83 , respectively). ${ }^{41}$

Mencucci et al conducted a prospective, observational study in patients with bilateral cataract and PEA $(n=120)$ who underwent unilateral cataract surgery. ${ }^{42}$ Patients were implanted with either spherical or toric IOLs. Postoperatively, patients with toric IOLs achieved significantly better refractive and visual outcomes compared to spherical IOLs. At 3 months after cataract surgery, QoL results were significantly better for the toric IOL group compared to the spherical IOL group, measured using the NEI RQL-42 questionnaire. Further, QoL was significantly better for the toric IOL group compared to the spherical IOL group, measured on NEI RQL subscales related to astigmatism correction, such as clarity of vision $(P<0.001)$, far vision $(P=0.021)$, glare $(P=0.038)$, and satisfaction with correction $(P=0.001){ }^{42}$

In a prospective single-arm study with a 6 -month follow-up, Knorz et al assessed patient experience with multifocal toric IOLs in Europe and South America ${ }^{43}$ The VISTAS questionnaire was administered preoperatively and at all postoperative visits. Preoperatively, $63 \%$ of astigmatic cataract patients were completely dissatisfied with their overall vision, which was reduced to $2.4 \%$ after astigmatism correction with multifocal toric IOLs. Preoperatively, only 14\% patients were spectacle-free, which had increased to $90 \%$ at 6 months after cataract surgery. On a scale of 0 (worst) to 10 (best), mean UCVA rating significantly improved from $3.63 \pm 1.98$ preoperatively $(\mathrm{n}=38)$ to $7.89 \pm 1.87$ at 6 months postoperatively $(\mathrm{n}=37)(P<0.001){ }^{43}$

Supuk et al conducted a prospective study in the UK to evaluate changes in dizziness and self-reported falls in cataract patients $(n=283)$ with astigmatism before and after cataract surgery (monofocal IOLs). The self-reported fall rate among patients in the 6 months prior to cataract surgery was $23 \%$ and had decreased to $20 \%$ at 6 months postsurgery; however, findings were statistically nonsignificant. Sensitivity analysis showed a nonsignificant association between fall risk and magnitude of astigmatism. ${ }^{44}$

Uncorrected astigmatism following cataract surgery appears to affect visual and refractive outcomes, leads to higher spectacle dependence, and is associated with low self-reported satisfaction with vision. This can in turn affect patients' vision-related QoL. A significant improvement in patient satisfaction was observed postsurgically after correction of astigmatism with toric IOLs. Postoperative spectacle dependence (defined as any use of spectacles) was lower with toric IOLs compared to monofocal IOLs. This review identified only one study that did not report any association between risk of falls and astigmatism.

\section{Discussion}

To our knowledge, this is the first systematic review to study the prevalence, humanistic burden, and economic burden of astigmatism in patients with cataract undergoing surgery. This systematic review aimed to synthesize the evidence on the prevalence and economic and humanistic burden of astigmatism in cataract patients.

Based on the available data, there is high prevalence of PEA in cataract patients. The economic burden of astigmatism in cataract patients is mostly driven by postoperative costs of vision correction with spectacles. In addition, indirect costs, such as optometrist, travel, and caregivers' time, add further to the economic burden on patients and their families. The evidence suggests that astigmatism correction at the time of cataract surgery resulted in better postoperative visual outcomes that can lead to higher satisfaction with vision, reduced need for vision correction with spectacles, and subsequent greater improvement in patients' vision-related QoL compared to patients in whom astigmatism correction is not attempted during cataract surgery. In addition, astigmatism correction during cataract surgery is a cost-effective or cost-saving approach compared to postoperative vision correction with spectacles.

Despite these benefits, patients in predominantly publicly financed health-care systems prevalent in Europe might not get access to astigmatism correction during cataract surgery, since cataract-surgery reimbursement is governed by fixed tariffs that cover only standard monofocal IOLs. Besides, astigmatism correction during cataract surgery may not be the ultimate clinical goal in many health-care systems, since 
it can be managed by vision correction with spectacles in the postoperative period.

Currently, public payers do not reimburse the cost of spectacles in many countries, and thus astigmatism correction is not covered in their budgets. Therefore, patients who want to have astigmatism correction during cataract surgery will have to be either covered by their private health-care insurance or will have to pay out of pocket. However, in some systems, such as the UK and Spain, there is no provision for patient copay in public hospitals, and thus patients have almost no choice in choosing the most effective treatment for their astigmatism. On the other side, cataract patients with PEA in predominantly private health-care insurance systems, such as the US, could have access to more effective treatments, such as toric IOLs. A recent study has highlighted the importance of understanding the differences in what patients say about the need for correction, what they do, and how they function with or without correction. All these important aspects should be considered in understanding the construct of spectacle independence. ${ }^{55}$

The evidence identified in this review had some inherent limitations. The data on prevalence of preoperative astigmatism has not been reported in many countries/regions, most significant of which is the US. The limited evidence on risk of falls and astigmatism in cataract patients suggests the need for more studies to investigate the risk. No population-based cost-of-illness study was identified, and the cost burden in preoperative astigmatic cataract patients is unknown. All the identified studies were interventional studies evaluating preoperative and postoperative economic and humanistic burden, meaning that study populations might not have been representative of astigmatic cataract patients. Further, we acknowledge that the reported economic burden in the published studies was an estimate from economic modeling methods, and then further discounting to 2017 prices could have led to an overestimation of cost data in our findings.

Nevertheless, this literature review has multiple strengths associated with the systematic review methodology. This review was conducted in accordance with the widely accepted Cochrane methodology. A comprehensive search strategy was used to identify the evidence from biomedical databases. In addition, conferences and bibliographies of included studies/literature reviews were hand-searched to identify any unpublished evidence. From a methodology perspective, limitations were mainly related to omission of non-English publications. Although we used a very long search period (1996-2016), some publications reporting data on prevalence and burden of astigmatism may have been missed.

\section{Conclusion}

There is high prevalence of PEA in cataract patients. Although published data are limited, both preoperative astigmatism and postoperative residual astigmatism affect visual function and vision-related QoL, resulting in increased humanistic burden. Suboptimal correction of astigmatism during cataract surgery drives the continuous need for vision correction with spectacles in the postoperative period. Patients must bear the out-of-pocket expenses, since payers often do not reimburse the cost of spectacles. Greater access to astigmatism correction during cataract surgery can improve visual outcomes and QoL in patients. More research is required to gain a better understanding of the disease burden of astigmatism in cataract patients.

\section{Acknowledgments}

Saisudha Samavedam and Syeda Safura Sultana, both employees of Novartis Healthcare Pvt Ltd, India, assisted with the literature search. Aldo A Martinez of Alcon Laboratories Inc, USA helped in the interpretation of findings from this review.

\section{Disclosure}

MD is an employee of Novartis. CB and MSK (at the time of research) are employees of Alcon. The authors report no other conflicts of interest in this work.

\section{References}

1. American Optometric Association. Optometric clinical practice guideline: care of the adult patient with cataract. 2004. Available from: http://www.aoa.org/documents/optometrists/CPG-8.pdf. Accessed January 22, 2017.

2. World Health Organization. Visual impairment and blindness. 2014. Available from: http://www.who.int/mediacentre/factsheets/fs282/en. Accessed November 14, 2016.

3. Read SA, Vincent SJ, Collins MJ. The visual and functional impacts of astigmatism and its clinical management. Ophthalmic Physiol Opt. 2014;34(3):267-294.

4. Narayanasamy S, Vincent SJ, Sampson GP, Wood JM. Simulated astigmatism impairs academic-related performance in children. Ophthalmic Physiol Opt. 2015;35(1):8-18.

5. Wills J, Gillett R, Eastwell E, et al. Effect of simulated astigmatic refractive error on reading performance in the young. Optom Vis Sci. 2012; 89(3):271-276.

6. Wolffsohn JS, Bhogal G, Shah S. Effect of uncorrected astigmatism on vision. J Cataract Refract Surg. 2011;37(3):454-460.

7. Higgins JP, Green S. Cochrane Handbook for Systematic Reviews of Interventions. Version 5.1.0. London: Cochrane Collaboration; 2011.

8. National Institute for Health and Care Excellence. Guide to the Methods of Technology Appraisal. London: NICE; 2013.

9. Moher D, Liberati A, Tetzlaff J, Altman DG. Preferred reporting items for systematic reviews and meta-analyses: the PRISMA statement. Ann Intern Med. 2009;151(4):264-269, W264.

10. Organisation for Economic Co-operation and Development. Inflation (CPI). 2017. Available from: https://data.oecd.org/price/inflation-cpi. htm. Accessed October 23, 2017. 
11. Bloomberg [website on the Internet]. Available from: https://www. bloomberg.com. Accessed November 10, 2017.

12. Reuters [website on the Internet]. Available from: http://reuters.com. Accessed November 10, 2017.

13. Behndig A, Montan P, Stenevi U, Kugelberg M, Zetterström C, Lundström M. Aiming for emmetropia after cataract surgery: Swedish National Cataract Register study. J Cataract Refract Surg. 2012;38(7): 1181-1186.

14. Chen W, Zuo C, Chen C, et al. Prevalence of corneal astigmatism before cataract surgery in Chinese patients. $J$ Cataract Refract Surg. 2013;39(2):188-192.

15. Cui Y, Meng Q, Guo H, et al. Biometry and corneal astigmatism in cataract surgery candidates from southern China. $J$ Cataract Refract Surg. 2014;40(10):1661-1669.

16. De Bernardo M, Zeppa L, Cennamo M, Iaccarino S, Zeppa L, Rosa N. Prevalence of corneal astigmatism before cataract surgery in Caucasian patients. Eur J Ophthalmol. 2014;24(4):494-500.

17. Ercegović A, Brajković J, Surać IK, Haluzan MB. Prevalence, distribution and types of corneal astigmatism in cataract surgery patients in Sibenik County. Acta Clin Croat. 2012;51(2):275-278.

18. Ferrer-Blasco T, Montes-Mico R, Peixoto-de-Matos SC, GonzalezMeijome JM, Cervino A. Prevalence of corneal astigmatism before cataract surgery. J Cataract Refract Surg. 2009;35(1):70-75.

19. Guan Z, Yuan F, Yuan YZ, Niu WR. Analysis of corneal astigmatism in cataract surgery candidates at a teaching hospital in Shanghai, China. J Cataract Refract Surg. 2012;38(11):1970-1977.

20. Cui Y, Meng Q, Guo H. Biometry and corneal astigmatism before phacoemulsification in southern China. Poster presented at: American Academy of Ophthalmology Annual Meeting; November 10-13, 2012; Chicago, IL.

21. Hoffmann PC, Hütz WW. Analysis of biometry and prevalence data for corneal astigmatism in 23,239 eyes. J Cataract Refract Surg. 2010; 36(9):1479-1485.

22. Khan MI, Muhtaseb M. Prevalence of corneal astigmatism in patients having routine cataract surgery at a teaching hospital in the United Kingdom. J Cataract Refract Surg. 2011;37(10):1751-1755.

23. Lekhanont K, Wuthisiri W, Chatchaipun P, Vongthongsri A. Prevalence of corneal astigmatism in cataract surgery candidates in Bangkok, Thailand. J Cataract Refract Surg. 2011;37(3):613-615.

24. Lyall DA, Srinivasan S, Ng J, Kerr E. Changes in corneal astigmatism among patients with visually significant cataract. Can J Ophthalmol. 2014;49(3):297-303.

25. Miyake T, Kamiya K, Amano R, Shimizu K. Corneal astigmatism before cataract surgery. Nippon Ganka Gakkai Zasshi. 2011;115(5):447-453.

26. Oh EH, Kim H, Lee HS, Hwang KY, Joo CK. Analysis of anterior corneal astigmatism before cataract surgery using power vector analysis in eyes of Korean patients. J Cataract Refract Surg. 2015;41(6): 1256-1263.

27. Ostri C, Falck L, Boberg-Ans G, Kessel L. The need for toric intraocular lens implantation in public ophthalmology departments. Acta Ophthalmol. 2015;93(5):e396-e397.

28. Prakairungthong N, Charukamnoetkanok P, Isipradit S. Prevalence of preoperative corneal astigmatism in patients undergoing cataract surgery at Mettapracharak Hospital, Thailand. J Med Assoc Thai. 2015; 98(9):878-882.

29. Riley AF, Grupcheva CN, Malik TY, Craig JP, McGhee CN. The Auckland Cataract Study: demographic, corneal topographic and ocular biometric parameters. Clin Exp Ophthalmol. 2001;29(6):381-386.

30. Westin O, Koskela T, Behndig A. Epidemiology and outcomes in refractive lens exchange surgery. Acta Ophthalmol. 2015;93(1):41-45.

31. Yuan X, Song H, Peng G, Hua X, Tang X. Prevalence of corneal astigmatism in patients before cataract surgery in northern China. J Ophthalmol. 2014;2014:536412.

32. Laurendeau C, Lafuma A, Berdeaux G. Modelling lifetime cost consequences of toric compared with standard IOLs in cataract surgery of astigmatic patients in four European countries. J Med Econ. 2009; 12(3):230-237.
33. Pineda R, Denevich S, Lee WC, Waycaster C, Pashos CL. Economic evaluation of toric intraocular lens: a short- and long-term decision analytic model. Arch Ophthalmol. 2010;128(7):834-840.

34. Ochoa F, Simbaqueba E, Romero M, Lopez A. Analysis of costeffectiveness of use of toric intraocular lenses compared with traditional monofocal lenses in patients with cataracts and pre-existing corneal astigmatism. Value Health. 2014;17(3):A286.

35. Kim H, Lim S, Cho B, et al. Astigmatism and cost of post-cataract surgery spectacle wear in Korea. Value Health. 2010;13(7):A563.

36. Colin X, Lafuma A, Berdeaux G. Cataract surgery cost in patients with and without astigmatism: a French national DRG database analysis. Value Health. 2009;12(7):A454.

37. Lane SS, Ernest P, Miller KM, Hileman KS, Harris B, Waycaster CR. Comparison of clinical and patient-reported outcomes with bilateral AcrySof toric or spherical control intraocular lenses. J Refract Surg. 2009;25(10):899-901.

38. Mingo-Botín D, Muñoz-Negrete FJ, Kim HR, Morcillo-Laiz R, Rebolleda G, Oblanca N. Comparison of toric intraocular lenses and peripheral corneal relaxing incisions to treat astigmatism during cataract surgery. J Cataract Refract Surg. 2010;36(10):1700-1708.

39. Holland E, Lane S, Horn JD, Ernest P, Arleo R, Miller KM. The AcrySof toric intraocular lens in subjects with cataracts and corneal astigmatism: a randomized, subject-masked, parallel-group, 1-year study. Ophthalmology. 2010;117(11):2104-2111.

40. Ahmed II, Rocha G, Slomovic AR, et al. Visual function and patient experience after bilateral implantation of toric intraocular lenses. J Cataract Refract Surg. 2010;36(4):609-616.

41. Visser N, Beckers HJ, Bauer NJ, et al. Toric vs aspherical control intraocular lenses in patients with cataract and corneal astigmatism: a randomized clinical trial. JAMA Ophthalmol. 2014;132(12):1462-1468.

42. Mencucci R, Giordano C, Favuzza E, Gicquel JJ, Spadea L, Menchini U. Astigmatism correction with toric intraocular lenses: wavefront aberrometry and quality of life. Br J Ophthalmol. 2013;97(5):578-582.

43. Knorz MC, Rincón JL, Suarez E, et al. Subjective outcomes after bilateral implantation of an apodized diffractive +3.0 D multifocal toric IOL in a prospective clinical study. $J$ Refract Surg. 2013;29(11):762-767.

44. Supuk E, Alderson A, Davey CJ, et al. Dizziness, but not falls rate, improves after routine cataract surgery: the role of refractive and spectacle changes. Ophthalmic Physiol Opt. 2016;36(2):183-190.

45. Asano K, Nomura H, Iwano M, et al. Relationship between astigmatism and aging in middle-aged and elderly Japanese. Jpn J Ophthalmol. 2005; 49(2):127-133.

46. Leung TW, Lam AK, Deng L, Kee CS. Characteristics of astigmatism as a function of age in a Hong Kong clinical population. Optom Vis Sci. 2012; 89(7):984-992.

47. Liu YC, Chou P, Wojciechowski R, et al. Power vector analysis of refractive, corneal, and internal astigmatism in an elderly Chinese population: the Shihpai Eye Study. Invest Ophthalmol Vis Sci. 2011; 52(13):9651-9657.

48. Sanfilippo PG, Yazar S, Kearns L, Sherwin JC, Hewitt AW, Mackey DA. Distribution of astigmatism as a function of age in an Australian population. Acta Ophthalmol. 2015;93(5):e377-e385.

49. Fattore G, Torbica A. Cost and reimbursement of cataract surgery in Europe: a cross-country comparison. Health Econ. 2008;17(1 Suppl): S71-S82.

50. Busbee BG, Brown MM, Brown GC, Sharma S. Incremental cost-effectiveness of initial cataract surgery. Ophthalmology. 2002;109(3):606-613.

51. American Academy of Ophthalmology Cataract and Anterior Segment Panel. Cataract in the adult eye PPP - 2011. 2011. Available from: www.aao.org/ppp. Accessed March 24, 2017.

52. Royal College of Ophthalmologists. Commissioning guide: cataract surgery. 2015. Available from: https://www.rcophth.ac.uk/publications/ commissioning-guide-cataract-surgery. Accessed March 24, 2017.

53. Royal College of Ophthalmologists. Cataract surgery guidelines. 2010. Available from: https://www.rcophth.ac.uk/wp-content/ uploads/2014/12/2010-SCI-069-Cataract-Surgery-Guidelines-2010SEPTEMBER-2010.pdf. Accessed November 10, 2017. 
54. Mo F, Choi BC, Li FC, Merrick J. Using Health Utility Index (HUI) for measuring the impact on health-related quality of Life (HRQL) among individuals with chronic diseases. ScientificWorldJournal. 2004;4: 746-757.
55. Morlock R, Wirth RJ, Tally SR, Garufis C, Heichel CW. Patient-Reported Spectacle Independence Questionnaire (PRSIQ): development and validation. American Journal of Ophthalmology. 2017;178:101-114.

\section{Publish your work in this journal}

Clinical Ophthalmology is an international, peer-reviewed journal covering all subspecialties within ophthalmology. Key topics include: Optometry; Visual science; Pharmacology and drug therapy in eye diseases; Basic Sciences; Primary and Secondary eye care; Patient Safety and Quality of Care Improvements. This journal is indexed on
PubMed Central and CAS, and is the official journal of The Society of Clinical Ophthalmology (SCO). The manuscript management system is completely online and includes a very quick and fair peer-review system, which is all easy to use. Visit http://www.dovepress.com/ testimonials.php to read real quotes from published authors. 